\title{
Improving wood volume predictions in dry tropical forest in the semi-arid Brazil
}

\author{
Robson B de LIMA ${ }^{*}$, Patrícia A B BARRETO-GARCIA ${ }^{2}$, Alessandro de PAULA ${ }^{2}$, \\ Jhuly E S PEREIRA ${ }^{3}$, Flávia F de CARVALHO ${ }^{2}$, Silvio H M GOMES ${ }^{4}$ \\ ${ }^{1}$ Department of Forest Engineering, State University of Amapá, Macapá 68900070, Brazil; \\ ${ }^{2}$ Department of Forest Science, State University of Southwest Bahia, Vitória da Conquista 45083900, Brazil; \\ ${ }^{3}$ Universidade Federal de Lavras, Lavras 37200900, Brazil; \\ ${ }^{4}$ Universidade de São Paulo, Piracicaba 13418900, Brazil
}

\begin{abstract}
The volumetric variability of dry tropical forests in Brazil and the scarcity of studies on the subject show the need for the development of techniques that make it possible to obtain adequate and accurate wood volume estimates. In this study, we analyzed a database of thinning trees from a forest management plan in the Contendas de Sincorá National Forest, southwestern Bahia State, Brazil. The data set included a total of 300 trees with a trunk diameter ranging from 5 to $52 \mathrm{~cm}$. Adjustments, validation and statistical selection of four volumetric models were performed. Due to the difference in height values for the same diameter and the low correlation between both variables, we do not suggest models which only use the diameter at breast height $(\mathrm{DBH})$ variable as a predictor because they accommodate the largest estimation errors. In comparing the best single entry model (Hohenald-Krenn) with the Spurr model (best fit model), it is noted that the exclusion of height as a predictor causes the values of 136.44 and 0.93 for Akaike information criterion (AIC) and adjusted determination coefficient $\left(\mathrm{R}_{\mathrm{adi}}^{2}\right)$, which are poorer than the second best model (Schumacher-Hall). Regarding the minimum sample size, errors in estimation (root mean square error (RMSE) and bias) of the best model decrease as the sample size increases, especially when a larger number of trees with $\mathrm{DBH} \geq 15.0 \mathrm{~cm}$ are randomly sampled. Stratified sampling by diameter class produces smaller volume prediction errors than random sampling, especially when considering all trees. In summary, the Spurr and Schumacher-Hall models perform better. These models suggest that the total variance explained in the estimates is not less than $95 \%$, producing reliable forecasts of the total volume with shell. Our estimates indicate that the bias around the average is not greater than $7 \%$. Our results support the decision to use regression methods to build models and estimate their parameters, seeking stratification strategies in diameter classes for the sample trees. Volume estimates with valid confidence intervals can be obtained using the Spurr model for the studied dry forest. Stratified sampling of the data set for model adjustment and selection is necessary, since we find significant results with mean error square root values and bias of up to $70 \%$ of the total database.
\end{abstract}

Keywords: volume modeling; minimal sample size; Caatinga; Spurr model; forest management

Citation: Robson B de LIMA, Patrícia A B BARRETO-GARCIA, Alessandro de PAULA, Jhuly E S PEREIRA, Flávia F de CARVALHO, Silvio H M GOMES. 2020. Improving wood volume predictions in dry tropical forest in the semi-arid Brazil. Journal of Arid Land, 12(6): 1046-1055. https://doi.org/10.1007/s40333-020-0082-x

\section{Introduction}

The Caatinga is an exclusively Brazilian biome occupying approximately $7 \%$ of the national

\footnotetext{
*Corresponding author: Robson B de LIMA (E-mail: rbl_florestal@yahoo.com.br)

Received 2020-07-07; revised 2020-09-23; accepted 2020-10-03

(C) Xinjiang Institute of Ecology and Geography, Chinese Academy of Sciences, Science Press and Springer-Verlag GmbH Germany, part of Springer Nature 2020
} 
territory and constitutes one of the largest semi-arid areas in the world (Miles et al., 2006; Queiroz, 2009; Araújo and Silva, 2010; Moro et al., 2016). The name Caatinga has indigenous origin (Tupi-Guarani) and its meaning (white forest, or mata branca in Portuguese) is associated with the open and gray aspect of the vegetation component (Moro et al., 2016), which is part of the group of seasonally dry tropical forests (Murphy and Lugo, 1986). These forests grow on soils ranging from clayey and shallow to sandy and underlying (Costa et al., 2014), and are resistant to up to 10 months of drought (Murphy and Lugo, 1995; Pennington et al., 2006; Dalmagro et al., 2014).

Forest ecosystems with complex mosaic distributed vegetation and high species' endemism, such as Caatinga dry tropical forests, are among the most fragmented and endangered in the world (Silva and Bates 2002; Miles et al., 2006; Werneck, 2011). Thus, studies related to monitoring, detecting and mapping environmental changes, as well as to obtaining estimates of forest parameters become of great importance in this scenario, since they support sustainable forest management, aiming at the conservation and maintenance of the services provided.

The wood volume present in a forest is a valuable information to elaborate sustainable forest management plans (SFMPs), as it is the basis for assessing the forest stock of a region and assists in planning forest exploitation (Leite and Resende, 2010). In Brazil, the Brazilian Institute of Environment and Renewable Natural Resources (IBAMA) requires that the volume of standing trees presented in SFMPs should be estimated using volumetric equations (Brasil, 2006).

Volumetric equations are usually obtained by adjusting mathematical models using regression techniques, and constitute the most adopted and efficient procedure for quantifying forest production (Cabacinha et al., 2013; Silva-Ribeiro et al., 2014). Many allometric equations have been developed for various vegetation types, but they are rarely validated in the field, especially for seasonally dry tropical forests such as Caatinga (Sampaio et al., 2010).

Studies related to volumetric modeling of dry forest phytophysiognomy trees are rare in the literature, despite its relevance as a shelter of remarkable biodiversity of fauna and flora (Albuquerque et al., 2012). Some authors also reported the difficulty of obtaining good allometric adjustments of individual trees of the predominant species in these phytophysiognomies, as they usually present tortuous trunks which fork near the ground (Lima et al., 1996). However, Souza et al. (2016) recommended the Schumacher-Hall and Spurr linear models to obtain stem volume estimates in typical Caatinga shrubby tree vegetation; and Lima et al. (2017) found that total volume estimates for Caatinga species in the state of Pernambuco are more accurate when dendrometric stem and branch variables are included in the model using the least squares method.

The different results found reveal the typical volumetric variability of Brazilian dry tropical forests conditioned by variations in stem shape, branch shape, density and genetic characteristics (Lima et al., 2017). There is a clear need to develop techniques for obtaining adequate and accurate volume estimates from tree sample volume data.

Herein, we analyzed a database of thinning trees from a forest management plan in the Contendas de Sincorá National Forest (FLONA), southwestern Bahia State, Brazil. Our data set included a total of 300 trees with trunk diameters ranging from 5 to $52 \mathrm{~cm}$. We addressed the following questions: (i) what is the best volumetric model in predicting volume with bark? (ii) what is the best tree sampling strategy to produce models? and (iii) how does the number of trees used in fitting affect forecast errors with respect to the performance of the best locally derived model?

\section{Materials and methods}

\subsection{Study area}

The study was conducted in an area of Caatinga forest $\left(13^{\circ} 55^{\prime} 21^{\prime \prime} \mathrm{S}, 41^{\circ} 06^{\prime} 57^{\prime \prime} \mathrm{W}\right)$ belonging to the FLONA, which has an area of about $1.10 \times 10^{4} \mathrm{hm}^{2}$ and is located in south of Chapada Diamantina, in the municipality of Contendas do Sincorá, southwestern Bahia State, Brazil. The vegetation is classified as savanna-steppe forest of arid land late successional stage, since the last intervention record in the area dates from 1997 (Ministry of the Environment, 2006; Brazilian Institute of Geography and Statistics, 2012). 
The local climate is semi-arid (BSwh) according to the Köppen classification, with well-defined dry season and annual mean temperature of $23.0^{\circ} \mathrm{C}$ (Alvares et al. 2013). The annual precipitation is between 596.0 and $678.5 \mathrm{~mm}$, with most distributed from November to April. The altitude range of the region is 295-380 $\mathrm{m}$ a.s.l., reaching $580 \mathrm{~m}$ a.s.l. in mountainous areas. The study area in the FLONA is located in the Resource Management Zone, determined by the Conservation Unit Management Plan (Ministry of the Environment, 2006), which provides for and encourages research and management programs.

\subsection{Tree sampling and volume determination}

We randomly selected 48 plots of $20 \mathrm{~m} \times 20 \mathrm{~m}\left(400 \mathrm{~m}^{2}\right)$ in order to understand the population diameter variation. We then measured the diameter at breast height (DBH) in each plot, taken at 1.3 $\mathrm{m}$ from the ground for all tree individuals with $\mathrm{DBH} \geq 5.0 \mathrm{~cm}$. We measured the diameter of all the stems originating below $1.3 \mathrm{~m}$, and used the quadratic diameter to obtain a single diameter per tree when a single tree had several stems (tillering). The stem DBH measurements were grouped into six diameter classes with an amplitude of eight centimeters, as shown in Table 1.

Table 1 Diametric distribution of tree stems in the dry tropical forest

\begin{tabular}{ccc}
\hline DBH classes $(\mathrm{cm})$ & Class center $(\mathrm{cm})$ & Frequency \\
\hline $5.0-13.0$ & 6.50 & 1.2 \\
$13.1-21.0$ & 17.05 & 96.0 \\
$21.1-29.0$ & 25.05 & 25.0 \\
$29.1-37.0$ & 33.05 & 7.0 \\
$37.1-45.0$ & 41.05 & 4.0 \\
$45.1-53.0$ & 49.05 & 2.0 \\
\hline
\end{tabular}

Note: DBH, diameter at breast height.

We rigorously measured the volume of 300 randomly selected trees distributed in different diameter classes proportionally to their frequencies (Table 1). We measured the diameters on each trunk with the bark at the $0.1,0.3,0.5,0.7,1.0,1.3$ and $2.0 \mathrm{~m}$ level positions from the soil using the Smalian method for calculating the volume. Then the sections were measured from this point at intervals of $1.0 \mathrm{~m}$ to the height where the diameter of three centimeters was, and then the length of the tip was measured. The total volume of each stem was obtained by summing the volume of all sections plus the tip volume, and then the total volume of each tree was obtained by the sum of the stem volumes.

We considered the height of the largest stem as the total height for individuals with more than one stem, and obtained the diameter equivalent to the height of $1.3 \mathrm{~m}(\mathrm{DEq})$ from the $\mathrm{DBH}$ of the multiple stem of each tree. The DEq assumes that the cross-sectional area $\left(\mathrm{m}^{2}\right)$ at $1.3 \mathrm{~m}$ of a multi-stem tree is equivalent to the sum of the individual cross-sectional areas of each stem and is defined by the root sum of squares of the stem DBH (Fraga et al., 2014).

\subsection{Fitting of volumetric models}

We tested two volumetric models based only on DBH and two combinations of DBH and height (H) commonly used to estimate trunk volume in the region:

$$
\text { Husch model: } \mathrm{VOL}=\beta_{0} \times \mathrm{DBH}^{\beta_{1}} \times \varepsilon,
$$

Hohenald-Krenn model: $\mathrm{VOL}=\beta_{0}+\beta_{1} \times \mathrm{DBH}+\beta_{2} \times \mathrm{DBH}^{2}+\varepsilon$,

$$
\text { Spurr model: } \mathrm{VOL}=\beta_{0}+\beta_{1} \times\left(\mathrm{DBH}^{2} \mathrm{H}\right)+\varepsilon \text {, }
$$

Schumacher-Hall model: $\ln (\mathrm{VOL})=\beta_{0}+\beta_{1} \times \ln (\mathrm{DBH})+\beta_{2} \times \ln (\mathrm{H})+\varepsilon$,

where VOL $\left(\mathrm{m}^{3}\right)$ is the volume with bark; $\beta_{i}$ is the parameter to be estimated; DBH $(\mathrm{cm})$ is the diameter at breast height measured at $1.3 \mathrm{~m}$ from trunk length; $\mathrm{H}(\mathrm{m})$ is the total height; and $\varepsilon$ is the random error.

The parameters of the Hohenald-Krenn, Spurr and Schumacher-Hall models were estimated 
using the Ordinary Least Squares (OLS) method. Husch's non-linear model was adjusted by modifying the Levenberg-Marquardt algorithm using the "minipack.lm" package. The parameters were generally calculated using the total tree population sampled in each plot and were assumed to be true parameters representing trunk volume.

The obtained equations were analyzed by comparing some statistical indices (Vanclay, 1994): Akaike information criterion (AIC), adjusted determination coefficient $\left(R_{\mathrm{adj}}^{2}\right)$, root mean square error (RMSE) and bias, with the formulas described below:

$$
\begin{gathered}
\mathrm{AIC}=-2 \mathrm{LL}+2 k, \\
R_{\mathrm{ddj}}^{2}=R^{2}-\left[\frac{k-1}{n-k}\right] \times\left(1-R^{2}\right), \\
\mathrm{RMSE}=\sqrt{\frac{\sum_{i=1}^{n}\left(V_{i}-\hat{V}_{i}\right)^{2}}{n},} \\
\mathrm{Bias}=\frac{\sum_{i=1}^{n}\left(V_{i}-\bar{V}_{i}\right)^{2}}{n} / \bar{V},
\end{gathered}
$$

where LL is the likelihood-log; $k$ is the number of model parameters; $R^{2}$ is the coefficient of determination; $n$ is the number of trees measured; $V_{i}\left(\mathrm{~m}^{3}\right)$ is the volume with individual bark $i ; \hat{V}_{i}$ $\left(\mathrm{m}^{3}\right)$ is the estimated volume with bark of the tree $i ; \bar{V}_{i}\left(\mathrm{~m}^{3}\right)$ is the arithmetic mean of volume with bark; and $\bar{V}$ is the mean volume.

\subsection{Minimum sample size for volumetric model development}

\subsubsection{Random sampling}

We iteratively generated sub-samples from the total dataset and from trees with DBH greater than $15.0 \mathrm{~cm}$, randomly selecting a sub-samples number and increasing the total number of trees by $20 \%, 50 \%$ and $70 \%$. We followed the best selected model assembly procedure (as described in Section 2.3) for volume estimates for each set of randomly sampled trees. As the random sampling produces highly variable adjusted parameters, we iterated random sampling 1000 times for each sample size and calculated the mean parameter in 1000 iterations to produce a single average estimate of $\beta_{0}$ (the constant angular parameter) and $\beta_{1}$ and $\beta_{2}$ (parameters) for each sample size, and to also generate the smallest error and bias measurements in the model calibration.

\subsubsection{Stratified random sampling}

We alternatively simulated a stratified random sampling of trees in six size classes (5.0-7.0, 7.0 9.0, 9.0-11.0, 11.0-13.0, 13.0-15.0 and $>15.0 \mathrm{~cm}$ ) for all trees with $\mathrm{DBH} \geq 5.0 \mathrm{~cm}$, and 15.0-20.0, $20.0-25.0,25.0-30.0$ and $>30.0 \mathrm{~cm}$ for trees with $\mathrm{DBH} \geq 15.0 \mathrm{~cm}$. Similarly, $20 \%, 50 \%$ and $70 \%$ of the trees within a given class were randomly chosen (Duncanson et al., 2015). The sample size was increased by selecting trees at random from both the total data and trees with $\mathrm{DBH} \geq 15.0 \mathrm{~cm}$. We also performed bootstrap in this procedure until we found the smallest measurements of error and bias in the model calibration. The best local model was developed for each subset and applied to the remaining data for cross validation.

We used R statistical software (R Development Core Team, 2019) in all computations and analyses.

\section{Results}

\subsection{Volumetric models}

Among the four adjusted volumetric models, the Spurr and Schumacher-Hall models present a better performance (smaller AIC; Table 2). These models suggest that the total variance explained in the estimates is not less than $95 \%\left(R_{\mathrm{adj}}^{2}\right)$, producing reliable predictions of the total volume with bark. Our estimates indicate that bias around the mean is not greater than $7 \%$ (bias=0.07; Table 2). 
Table 2 Estimates of parameters and adequacy indices of four volumetric models of individual trees adjusted for the dry tropical forest

\begin{tabular}{ccccrcccc}
\hline Model & $\square \beta_{0}( \pm \mathrm{SE})$ & $\square \beta_{1}( \pm \mathrm{SE})$ & $\square \beta_{2}( \pm \mathrm{SE})$ & \multicolumn{1}{c}{ AIC } & RSE & $R_{\text {adj }}^{2}$ & RMSE & Bias \\
\hline Husch & $-8.613( \pm 0.082)$ & $2.303( \pm 0.036)$ & - & 141.45 & 0.30 & 0.93 & 0.06 & 0.10 \\
Hohenald-Krenn & $-9.504( \pm 0.346)$ & $3.058( \pm 0.286)$ & $-0.151( \pm 0.057)$ & 136.44 & 0.30 & 0.93 & 0.04 & 0.09 \\
Spurr & $-9.914( \pm 0.089)$ & $1.013( \pm 0.013)$ & - & 58.88 & 0.27 & 0.95 & 0.06 & 0.07 \\
Schumacher-Hall & $-9.792( \pm 0.140)$ & $2.060( \pm 0.040)$ & $0.909( \pm 0.092)$ & 59.60 & 0.27 & 0.95 & 0.06 & 0.07 \\
\hline
\end{tabular}

Note: $\beta_{i}$, the parameter of the models adjusted with their respective confidence intervals obtained by standard error of the mean $(P>0.05)$; SE, standard error; AIC, Akaike information criteria; RSE, residual standard error; RMSE, root mean square error; -, no data available.

None of the adjusted models shows lack of fit according to the F-test. All selected models present parameters with valid confidence intervals $(P>0.05)$. Although the volume estimate is similar for the range of trees up to $25.0 \mathrm{~cm}$ in diameter for all four models (Fig. 1), there is a noticeable divergence for the other diameter ranges. This can be caused mainly by the height data in which double entry models result in significantly lower percentage biases than models that do not include height.
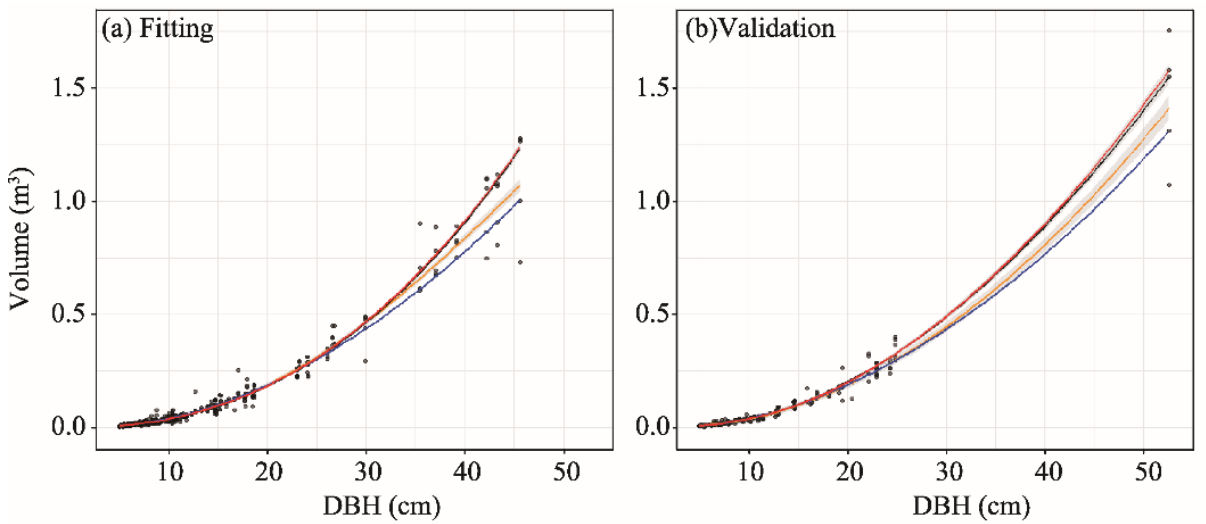

Husch model $\rightarrow$ Hohenald-Krenn model

Spurr model

Schumacher-Hall model

Fig. 1 Fitting (a) and validation (b) regression curves (color lines) and 95\% CIs (CIs, confidence intervals; grey envelopes) of four models (detailed in Table 1) relating volume and diameter at breast height (DBH) of trees in the dry tropical forest

Due to the difference in height values for the same diameter and the low correlation between both variables, we do not suggest models which only use the $\mathrm{DBH}$ variable as a predictor because they accommodate the largest estimation errors. In comparing the best single entry model (Hohenald-Krenn) with the Spurr model (best fit model), it is noted that the exclusion of height as a predictor causes the AIC of 136.44 and the $R_{\text {adj }}^{2}$ of 0.93 , which are poorer than the second best model (Schumacher-Hall). Therefore, our results suggest that it is more parsimonious to maintain a volumetric Spurr model obtained for the entire FLONA.

The Spurr equation predicts that logarithmic transformation of the combination of tree diameter and height variables for a given volume decreases the bias in the estimate. The functional form of the equations tested is biologically consistent, especially with the inclusion of the height variable, and these results can be illustrated in the residual distribution (Fig. 2).

\subsection{Minimum sample size}

Regarding the minimum sample size, there are three important and visible trends shown in Table 3 and Figure 3. First, errors in estimation (RMSE and bias) of the best model decrease as the sample size increases, especially when a larger number of trees with $\mathrm{DBH} \geq 15.0 \mathrm{~cm}$ are randomly sampled. Second, stratified sampling by diameter class produces smaller volume prediction errors than random sampling, especially when considering all trees. This is most evident when we evaluate the minimized values of the differences between predicted and observed data. We further note that a 

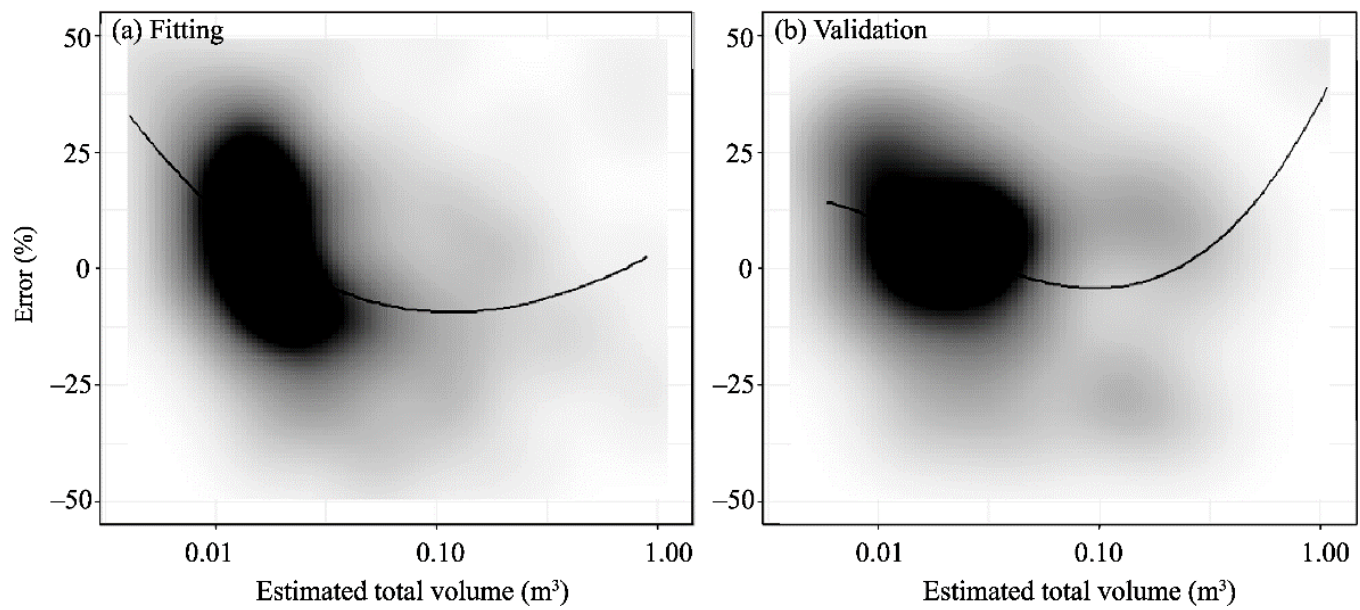

Fig. 2 Residual distribution of wood volume for the best equation (Spurr) obtained for the trees in the dry tropical forest. (a), fitting; (b), validation.

significant error reduction occurs up to a $50 \%$ sample size considering random sampling of both all trees and those with $\mathrm{DBH}>15.0 \mathrm{~cm}$, while the size of up to $70 \%$ maintains a large mean difference for all trees considering stratified sampling (see bias in Table 3). Third, there is a considerable variability in volume estimates for the area, and this variability also decreases with increased sample size percentage.

Table 3 Statistical criteria for different tree sampling strategies

\begin{tabular}{cccccc}
\hline Sampling strategy & RMSE & RSE & CV (\%) & Bias & Percentile (\%) \\
\hline All trees (stratified) & 0.0559 & 0.2644 & 65 & -0.0710 & 20 \\
All trees (stratified) & 0.0549 & 0.2632 & 63 & -0.2452 & 50 \\
All trees (stratified) & 0.0541 & 0.2642 & 63 & -0.0851 & 70 \\
DBH>15.0 cm (stratified) & 0.1120 & 0.2681 & 38 & 0.4497 & 20 \\
DBH>15.0 cm (stratified) & 0.1066 & 0.2672 & 36 & -0.4606 & 50 \\
DBH $>15.0$ cm (stratified) & 0.1083 & 0.2715 & 37 & -0.3180 & 70 \\
DBH $>15.0$ cm (random) & 0.2400 & 0.2668 & 81 & 9.4526 & 20 \\
DBH $>15.0$ cm (random) & 0.1373 & 0.2806 & 46 & 3.8118 & 50 \\
DBH $>15.0$ cm (random) & 0.1345 & 0.2804 & 45 & 3.5025 & 70 \\
\hline
\end{tabular}

Note: RMSE, root mean square error; RSE, residual standard error; CV, coefficient of variation.
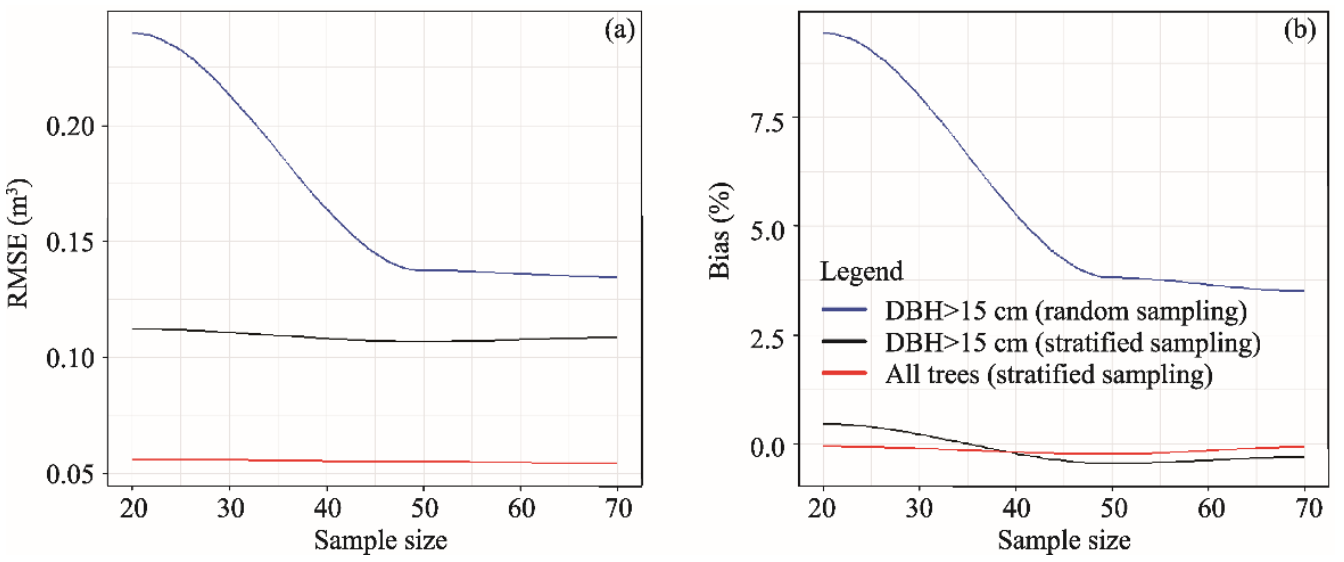

Fig. 3 Root mean square error (RMSE; a) and bias (b) of estimated total volume using different percentiles of data size to adjust and validate the best local model 


\section{Discussion}

Theoretically, regression analysis has been used with emphasis on solving most forest problems, especially when estimating forest parameters through biometric relationships (Robinson and Hamannn, 2011; Burkhart and Tomé, 2012; Lima et al., 2014). The use of regression models that can accurately determine forest production based on wood volume estimation is critical to implementing sustainable management (Berger et al., 2014; McRoberts and Westfall, 2014); this allows estimates of the monetary value of forests (Burkhart and Tomé, 2012).

Logarithmic models have been constantly used in studying biometric relationships, mainly for developing biomass and volume equations in natural forests (Chave et al., 2005; Segura and Kanninen, 2005; Litton and Boone Kauffman, 2008; Basuki et al., 2009). These models are often generally used in Brazil and particularly in the different tropical dry forests (Lima et al., 2017), although few studies have applied the volume transformation from the logarithmic scale to the original scale using the correction factor (Vibrans et al., 2015). In addition, robust methods for leveraging model fit quality such as AIC or Bayesian information criteria are rarely used and should be incorporated into statistical model fit routines (Zeng and Tang, 2011). Our results support the decision to use regression methods to build models and estimate their parameters.

While much of the variation in volume is explained by diameter alone, and the improvement is relatively significant when the height variable is included. Overall, all of the statistical evaluation criteria reveal that double-entry equations show a greater accuracy in predictions, especially the equation obtained from the Spurr model. Therefore, our results indicate the inclusion of the height variable in the volume estimate, since single entry models assume that trees of different diameter sizes have the same heights, which is not true for tropical forests (Brando, 2018; Sullivan et al., 2018).

However, it is important to ensure that the predominant tree growth forms and architecture are represented among the sampled trees used to develop the volumetric model (Duncanson et al., 2015). The accuracy of volume predictions tends to be improved by including height as an explanatory variable in using appropriate tree sample and small measurement errors, despite the added uncertainty using a height and diameter model (Kachamba and Eid, 2016).

Regarding the minimum sample size, we generally notice that stratified sampling presents a higher precision than random sampling, especially when considering trees with $\mathrm{DBH}>15.0 \mathrm{~cm}$ in the adjustment of the models. This is because random sampling distorts the sampling for trees with $\mathrm{DBH} \geq 15.0 \mathrm{~cm}$, causing larger errors in the simulations and allowing a less representative sample for smaller trees (Duncanson et al., 2015).

Focusing on the results of stratified sampling, as these are probably more representative of forest measurement, it can be observed that the sample size of $70 \%$ of the total trees is in agreement with the average sampling obtained by Jenkins et al. (2003) and Duncanson et al. (2015). In stratified sampling, all trees and for trees with $\mathrm{DBH} \geq 15.0 \mathrm{~cm}$ are likely to have higher mean prediction errors because they simulate a low number of trees per diameter class, and volume estimation biases will increase with small sample size (Sullivan et al., 2018). The higher proportion of trees in the stratified sampling yields a more reliable volume estimate at the $70 \%$ level of data. Therefore, our results suggest that stratifying data across different DBH size classes is the most efficient way to develop a generic volumetric model.

This work seeks to fill the gap about the validity of volumetric equations developed for dry tropical forests, although some research has already suggested the development of individual equations for species (Abreu et al., 2016). The issue currently being discussed and reported in this paper is whether it would be better to use generic volume equations or form factors from other locations, or to develop site-specific equations in locations where no generic volumetric equation is available.

However, there is a lack of guidelines for selecting existing volumetric models and validating alternatives. The limiting factor has always been the destructive sampling of trees for model adjustment and selection (Chave et al., 2014). Highly accurate estimates of individual tree volumes and biomasses are increasingly available through Lidar technology (Watt et al., 2013; Levick et al., 
2016; Oliveira et al., 2018). These estimates do not require destructive tree sampling and can be performed systematically in the field (Duncanson et al., 2015, 2017; Duncanson and Dubayah, 2018). A system could be developed to adequately sample tree volume data in situ at environmental gradients with appropriate sampling, providing a potential solution to outstanding problems related to forest biomass and carbon stock.

\section{Conclusions}

Volume estimates with valid confidence intervals can be obtained by the Spurr model for the FLONA. Stratified sampling by diameter class for model adjustment and selection was proved to be necessary, since we found significant results with lower RMSE and bias values for up to $70 \%$ of the total database and also when only considering trees with $\mathrm{DBH}>15.0 \mathrm{~cm}$. These results can be used by forest managers as a technical tool in predicting the volume of dry tropical forests in southwestern Bahia State, Brazil. Further studies should clarify the mechanisms for developing specific equations at the ecological group, family and commercial species levels.

\section{Acknowledgements}

Special thanks to the National Council for Scientific and Technological Development-CNPq for granting financial support to the project (484260/2013-8).

\section{References}

Abreu J C, Silva J A A, Ferreira R L C, et al. 2016. Setting linear and nonlinear mathematical models for biomass estimate and nutrients in Anadenanthera colubrina var. cebil in the semiarid region of Pernambuco. Scientia Forestalis, 44(111): 739-750. (in Brazilian)

Albuquerque U P, Araújo E L, El-Deir A C A, et al. 2012. Caatinga revisited: ecology and conservation of an important seasonal dry forest. Scientific World Journal, 2012: e205182, doi: 10.1100/2012/205182.

Alvares C A, Stape J L, Sentelhas P C, et al. 2013. Köppen climate classification map for Brazil. Meteorologische Zeitschrift, 22(6): 711-728. (in Brazilian)

Araújo L V C, Silva J A. 2010. Belo Horizonte farm experimental unit-Mossoró/RN. In: Gariglio M A, Sampaio E V S B, Cestaro L A, et al. Sustainable Use and Conservation of Caatinga Forest Resources. Brazilian Forest Service, 205-214. (in Brazilian)

Basuki T M, van Laake P E, Skidmore A K, et al. 2009. Allometric equations for estimating the above-ground biomass in tropical lowland Dipterocarp forests. Forest Ecology and Management, 257(8): 1684-1694.

Berger A, Gschwantner T, Mcroberts R E, et al. 2014. Effects of measurement errors on individual tree stem volume estimates for the Austrian national forest inventory. Forest Science, 60(1): 14-24.

Brando P. 2018. Tree height matters. Nature Geoscience, 11(1): 390-391.

Brasil. 2006. Normative Instruction, No. 5 of December 11. Provides for technical procedures for the preparation, execution and technical evaluation of sustainable forest management plans. [2020-04-24]. https://www.mma.gov.br/estruturas/pnf/_arquivos/in\%20mma\%2004-06.pdf. (in Brazilian)

Brazilian Institute of Geography and Statistics. 2012. Technical Manual of the Brazilian vegetation (2 $\left.{ }^{\text {nd }}\right)$. Rio de Janeiro, Brazil, 271. (in Brazilian)

Burkhart H E, Tomé M. 2012. Modeling Forest Trees and Stands. Dordrecht: Springer Netherlands, 1-460.

Cabacinha C D, Scolforo J R S, Thiersch, C R, et al. 2013. A new approach for the geometric method using the parabola index method. Ciência Florestal, 23(1): 261-271. (in Brazilian)

Chave J, Andalo C, Brown S, et al. 2005. Tree allometry and improved estimation of carbon stocks and balance in tropical forests. Oecologia, 145(6): 87-99.

Chave J, Réjou-Méchain M, Búrquez A, et al. 2014. Improved allometric models to estimate the aboveground biomass of tropical trees. Global Change Biology, 20(10): 3177-3190.

Costa T L, Sampaio E V S B, Sales M F, et al. 2014. Root and shoot biomasses in the tropical dry forest of semi-arid Northeast Brazil. Plant and Soil, 378: 113-123.

Dalmagro H J, Lobo F D A, Vourlitis G L, et al. 2014. The physiological light response of two tree species across a hydrologic 
gradient in Brazilian savanna (Cerrado). Photosynthetica, 52(1): 22-35.

Duncanson L, Rourke O, Dubayah R. 2015. Small sample sizes yield biased allometric equations in temperate forests. Scientific Reports, 5: 17153, doi: 10.1038/srep17153.

Duncanson L, Huang W, Johnson K, et al. 2017. Implications of allometric model selection for county-level biomass mapping. Carbon Balance and Management, 12(18): 1-11.

Duncanson L, Dubayah R. 2018. Monitoring individual tree-based change with airborne lidar. Ecology and Evolution, 8(10): 5079-5089.

Fraga M P, Barreto P A B, de Paula A. 2014. Volume estimation of Pterogyne nitens in pure plantation in the southwest of Bahia. Embrapa Forestry, 34(79): 207-215. (in Brazilian)

Jenkins J C, Chojnacky D C, Heath L S, et al. 2003. National-scale biomass estimators for United States tree species. Forest Science, 49(1): 12-35.

Kachamba D J, Eid T. 2016. Total tree, merchantable stem and branch volume models for miombo woodlands of Malawi. Southern Forests, 78(1): 41-51.

Leite F S L, Resende A V. 2010. Estimate of wood volume departing from the diameter at stump height in an exploited area in "terra firme" amazon forest. Ciência Florestal, 20(1): 69-79. (in Brazilian)

Levick S R, Hessenmöller D, Schulze E. 2016. Scaling wood volume estimates from inventory plots to landscapes with airborne LiDAR in temperate deciduous forest. Carbon Balance and Management, 11(7): 1-14.

Lima P C F, Oliveira E B, Machado S A. 1996 Equations for biomass estimation of Prosopis species in the brazilian semi-arid region. Boletim de Pesquisa Florestal, 32(33): 67-79. (in Brazilian)

Lima R B, Aparício P S, Ferreira R L C, et al. 2014. Volumetry and classification of production capacity for Mora paraensis (Ducke) in Amapa estuary. Scientia Forestalis, 42(101): 141-154. (in Brazilian)

Lima R B, Alves Júnior F T, Oliveira C P D, et al. 2017. Predicting of biomass in Brazilian tropical dry forest: a statistical evaluation of generic equations. Anais da Academia Brasileira de Ciências, 89(3): 1815-1828.

Litton C M, Boone K J. 2008. Allometric models for predicting aboveground biomass in two widespread woody plants in Hawaii. Biotropica, 40(3): 313-320.

Mcroberts R E, Westfall J A. 2014. Effects of uncertainty in model predictions of individual tree volume on large area volume estimates. Forest Science, 60(1): 34-42.

Miles L, Newton A C, Defries R S, et al. 2006. A global overview of the conservation status of tropical dry forests. Journal of Biogeography, 33(3): 491-505.

Ministry of the Environment. 2006. National Forest Management Plan Contendas do Sincorá. Volume I: General Information about the National Forest. Brasília: Brazilian Institute of Environment and Renewable Natural Resources, 132. (in Brazilian)

Moro M F, Lughadha E N, Araújo F S, et al. 2016. A Phytogeographical metaanalysis of the semiarid Caatinga domain in Brazil. The Botanical Review, 82(2): 91-148.

Murphy P G, Lugo A E. 1986. Ecology of tropical dry forest. Annual Review of Ecology and Systematics, 17(1): 67-88.

Murphy P G, Lugo A E. 1995. Dry forests of Central America and the Caribbean. In: Bullock S, Mooney H, Medina E. Seasonally Dry Tropical Forests. California: University Press, 9-34.

Oliveira L Z, Klitzke A R, Fantini A, et al. 2018. Robust volumetric models for supporting the management of secondary forest stands in the Southern Brazilian Atlantic Forest. Anais da Academia Brasileira de Ciências, 90(4): 3729-3744. (in Brazilian)

Pennington R T, Lewis G P, Ratter J A. 2006. An overview of the plant diversity, biogeography and conservation of Neotropical Savannas and seasonally dry forests. In: Pennington R T, Lewis G P, Ratter J A. Neotropical Savannas and Seasonally Dry Forests: Plant Diversity, Biogeography, and Conservation. Boca Raton: CRC Press, 1-29.

Queiroz L P. 2009. Leguminous of Caatinga. Feira de Santana: UEFS, 443. (in Brazilian)

R Development Core Team. 2019. R: A Language and Environment for Statistical Computing. Vienna: R Foundation for Statistical Computing. [2020-04-24]. http://www.R-project.org/.

Robinson A P, Hamann J D. 2011. Forest Analytics with R. New York: Springer, 1-311.

Sampaio E, Gasson P, Baracat A, et al. 2010. Tree biomass estimation in regenerating areas of tropical dry vegetation in northeast Brazil. Forest Ecology and Management, 259(6): 1135-1140.

Segura M, Kanninen M. 2005. Allometric models for tree volume and total aboveground biomass in a tropical humid forest in Costa Rica. Biotropica, 37(1): 2-8.

Silva J M C, Bates J M. 2002. Biogeographic patterns and conservation in the South American Cerrado: A tropical Savanna hotspot. BioScience, 52(3): 225-234. 
Silva-Ribeiro R B, Gama J R V, Melo L O. 2014. Sectional analysis for volume determination and selection of volume equations for the Tapajos Nacional Forest. Cerne, 20(4): 605-612. (in Brazilian)

Souza P F, Silva J A, Lucena D S, et al. 2016. Dendrometric and phytosociological studies in a fragment of caatinga, São José de Espinharas - PB. Ciência Florestal, 26(4): 1317-1330. (in Brazilian)

Sullivan M J P, Lewis S L, Hubau W, et al. 2018. Field methods for sampling tree height for tropical forest biomass estimation. Methods in Ecology and Evolution, 9(5): 1179-1189.

Vanclay J K. 1994. Modelling Forest Growth and Yield: Applications to Mixed Tropical Forests. Oxford: CAB International, 1330.

Vibrans A C, Moser P, Oliveira L Z, et al. 2015. Generic and specific stem volume models for three subtropical forest types in southern Brazil. Annals of Forest Science, 72: 865-874.

Watt M S, Adams T, Gonzalez-Aracil S, et al. 2013. The influence of LiDAR pulse density and plot size on the accuracy of New Zealand plantation stand volume equations. New Zealand Journal of Forestry Science, 43(15): 1-10.

Werneck F P. 2011. The diversification of eastern South American open vegetation biomes: historical biogeography and perspectives. Quaternary Science Reviews, 30(13-14): 1630-1648.

Zeng W S, Tang S Z. 2011. Bias correction in logarithmic regression and comparison with weighted regression for nonlinear models. Nature Precedings, 24(2): 137-143. 